\title{
Randomised phase II study of ASA404 combined with carboplatin and paclitaxel in previously untreated advanced non-small cell lung
}

\section{cancer}

\author{
MJ McKeage*,I, J Von Pawel ${ }^{2}$, M Reck ${ }^{3}$, MB Jameson ${ }^{4}$, MA Rosenthal ${ }^{5}$, R Sullivan ${ }^{6}$, D Gibbs ${ }^{7}$, PN Mainwaring ${ }^{8}$, \\ M Serke', J-J Lafitte ${ }^{10}$, C Chouaid'", L Freitag' ${ }^{12}$ and E Quoix ${ }^{13}$ \\ 'University of Auckland, 85 Park Road, Grafton, Private Bag 92019. Auckland I 142, New Zealand; ${ }^{2}$ Asklepios Fachkliniken, Robert-Koch-Allee 2, \\ D-82 I 3 I Gauting, Germany; ${ }^{3}$ Krankenhaus Grosshansdorf, Woehrendamm 80, D-22927 Grosshansdorf, Germany; ${ }^{4}$ Waikato Hospital, Private Bag \\ 3200, Hamilton, New Zealand; ${ }^{5}$ Royal Melbourne Hospital, Melbourne 3050, Victoria, Australia; ${ }^{6}$ Auckland City Hospital, 2 Park Road, Grafton, \\ Auckland 1023, New Zealand; ${ }^{7}$ Christchurch Hospital, Private Bag 4710, Christchurch, New Zealand; ${ }^{8}$ Mater Health Services, Brisbane 4101 , \\ Queensland, Australia; ${ }^{\circ}$ Helios Klinikum Emil von Behring, Lungenklinik Heckeshom, Walterhöferstrasse II, D-14165 Berlin, Germany; ${ }^{10}$ Hôpital \\ Calmette Senvice de Pneumologie, Boulevard du professeur Jules Leclercq, 59037 Lille, France; 'I'Hôpital Saint Antoine, 184, rue du Faubourg, Saint \\ Antoine, 7557I Paris Cedex, France; ' 2 Lungenklinik Hemer, Theo-Funccius-Strasse I, D-58675 Hemer, Germany; ${ }^{3}$ Service de Pneumologie, Hôpitaux \\ Universitaires, 67091 Strasbourg Cedex, France
}

ASA404 (5,6-dimethylxanthenone-4-acetic acid or DMXAA) is a small-molecule tumour-vascular disrupting agent (Tumour-VDA). This randomised phase II study evaluated ASA404 plus standard therapy of carboplatin and paclitaxel in patients with histologically confirmed stage IIIb or IV non-small cell lung cancer (NSCLC) not previously treated with chemotherapy. Patients were randomised to receive $\leqslant 6$ cycles of carboplatin area under the plasma concentration-time curve $6 \mathrm{mg} \mathrm{ml}^{-1} \mathrm{~min}$ and paclitaxel $175 \mathrm{mg} \mathrm{m}^{-2}(\mathrm{CP}$, $n=36$ ) or standard therapy plus ASA404 $1200 \mathrm{mg} \mathrm{m}^{-2}$ (ASA404-CP, $n=37$ ). There was little change in the systemic exposure of either total or free carboplatin or paclitaxel on addition of ASA404. Safety profiles were similar and manageable in both groups, with most adverse effects attributed to standard therapy. Tumour response rate (3I vs 22\%), median time to tumour progression (5.4 vs 4.4 months) and median survival (14.0 vs 8.8 months, hazard ratio $0.73,95 \% \mathrm{Cl} 0.39$, I.38) were improved in the ASA404 combination group compared with the standard therapy group. In conclusion, this study establishes the feasibility of combining ASA404 with carboplatin and paclitaxel in patients with previously untreated, advanced NSCLC, demonstrating a manageable safety profile and lack of adverse pharmacokinetic interactions. The results indicate that there may be a benefit associated with ASA404, but this needs to be evaluated in a larger trial.

British Journal of Cancer (2008) 99, 2006 -2012. doi:10.1038/sj.bjc.6604808 www.bjcancer.com

(C) 2008 Cancer Research UK

Keywords: ASA404; ASI404; DMXAA; VDA; tumour-VDA; non-small cell lung cancer

The mainstay of treatment for advanced non-small cell lung cancer (NSCLC) is platinum-based chemotherapy (Non-Small Cell Lung Cancer Collaborative Group, 1995), often combined with paclitaxel (Langer et al, 1995). However, an efficacy plateau has been reached with chemotherapy; no regimen is clearly superior (Schiller et al, 2002), and adding a third cytotoxic agent increases toxicity without improving outcome (Wakelee and Belani, 2005).

A new treatment strategy under investigation involves targeting tumour vasculature with small-molecule vascular disrupting agents (VDAs), such as the tubulin-depolymerising combretastatin A-4-phosphate (C4AP) (Dowlati et al, 2002; Stevenson et al, 2003; Rustin et al, 2003b) and the microtubule-independent ASA404 (5,6-dimethylxanthenone-4-acetic acid (DMXAA)), or anti-angiogenic agents, such as the antibody bevacizumab. In a phase III

*Correspondence: Dr M McKeage; E-mail: m.mckeage@auckland.ac.nz Received 14 July 2008; revised 5 November 2008; accepted 8 November 2008 study, the combination of carboplatin, paclitaxel and bevacizumab improved survival significantly compared with carboplatin and paclitaxel alone in patients with advanced NSCLC of nonsquamous histology (Sandler et al, 2006).

The tumour-VDA, ASA404, induces apoptosis of tumour vascular endothelial cells and cytokine production, leading to tumour vascular collapse (Ching et al, 2002; Baguley, 2003; Tozer et al, 2005). In animal models, this culminates in extensive tumour necrosis predominantly within the tumour core (Zwi et al, 1994; Laws et al, 1995; Ching et al, 1999, 2004; Joseph et al, 1999). The therapeutic potential of ASA404 appears to lie in its combination with other treatments (Wilson et al, 1998; Murata et al, 2001). In animal models, ASA404 acted synergistically with chemotherapy (Pruijn et al, 1997; Siim et al, 2003; McKeage and Kelland, 2006); therapeutic gains were most striking with taxanes. Scheduling studies indicated that activity was optimised when ASA404 was administered shortly after chemotherapy (Siim et al, 2003). 
In two phase I trials, 109 patients received ASA404 monotherapy at doses of $6-4900 \mathrm{mg} \mathrm{m}^{-2}$ weekly or every 3 weeks (Jameson et al, 2003; Rustin et al, 2003a). ASA404 did not cause myelosuppression and was generally well tolerated. Transient prolongation of heart rate-corrected cardiac QT interval (QTc) was seen at high doses $\left(\geqslant 2000 \mathrm{mg} \mathrm{m}^{-2}\right)$. Transient, dose-dependent visual disturbances were also noted. Dose-limiting toxicities were rapidly reversible and included confusion, tremor, slurred speech, visual disturbance, anxiety, urinary incontinence and possible left ventricular failure. The maximum tolerated dose (MTD) was $3700 \mathrm{mg} \mathrm{m}^{-2}$. ASA404 produced two unconfirmed partial responses at 1100 and $1300 \mathrm{mg} \mathrm{m}^{-2}$, and 28 patients had a best response of stable disease. Dynamic contrast-enhanced magnetic resonance imaging showed reductions in tumour blood flow at sub-MTD doses (Galbraith et al, 2002). A third phase I study investigated the potential for cardiac and ophthalmic toxicity and found ASA404 doses of 1200 and $1800 \mathrm{mg} \mathrm{m}^{-2}$ to be well tolerated, with no significant effect on QTc interval or deterioration in ophthalmic variables (McKeage et al, 2006). Near-maximal levels of the tumour vascular damage biomarker 5-hydroxyindoleacetic acid (5-HIAA) were seen at these doses (Baguley et al, 1997), and ASA404 plasma concentrations were within the preclinical therapeutic range (McKeage et al, 1991).

We conducted this randomised phase II study to determine the feasibility of combining ASA404 $1200 \mathrm{mg} \mathrm{m}^{-2}$ with carboplatin and paclitaxel, to examine the potential for pharmacokinetic interactions between components of this regimen and to evaluate its safety and efficacy in patients with previously untreated advanced NSCLC.

\section{MATERIALS AND METHODS}

Men and women $\geqslant 18$ years with histologically confirmed, locally advanced or metastatic NSCLC (stage IIIb/IV, incurable by surgery/radiotherapy), with $\geqslant 1$ unidimensionally measurable lesion according to the Response Evaluation Criteria in Solid Tumors (RECIST) (Therasse et al, 2000) and no previous chemotherapy were eligible. Other requirements included Karnofsky performance status $\geqslant 70 \%$, life expectancy $\geqslant 3$ months and adequate haematological, renal and hepatic function.

Main exclusion criteria were major surgery/radiotherapy (unless palliative) $\leqslant 4$ weeks before enrolment, central nervous system metastases, small cell or mixed lung cancer, clinically significant cardiac arrhythmia or known QTc interval prolongation, severe or uncontrolled systemic disease, pregnancy, use of medication known to affect systemic serotonin levels or QTc interval $\leqslant 2$ weeks before ASA404 administration or an expected need for such treatment during the study.

Patients were recruited from 15 centres in New Zealand, Australia, Germany and France. The study was conducted according to the Declaration of Helsinki. Ethics committee approval and informed patient consent were obtained.

\section{Study design}

This randomised, open-label, phase II study tested the addition of ASA404 $1200 \mathrm{mg} \mathrm{m}^{-2}$ to a standard therapy regimen comprising carboplatin dosed to area under the plasma concentration-time curve (AUC) $6 \mathrm{mg} \mathrm{ml}^{-1} \mathrm{~min}$ plus paclitaxel at an FDA-approved dose of $175 \mathrm{mg} \mathrm{m}^{-2}$.

Patients were allocated to receive ASA404 $1200 \mathrm{mg} \mathrm{m}^{-2}$ plus carboplatin and paclitaxel (ASA404-CP) or carboplatin and paclitaxel alone (CP). Randomisation was conducted centrally, with stratification for disease stage, performance status and histological type. On day 1 of each cycle, patients received paclitaxel as a 3-h IV infusion, then carboplatin as a $30-\mathrm{min}$ IV infusion, then, if allocated, ASA404 as a 20 -min IV infusion.
As this was the first experience of ASA404 in combination with carboplatin and paclitaxel in humans, a single patient received the combination with ASA404 at a lower dose of $600 \mathrm{mg} \mathrm{m}^{-2}$ (six cycles) to check safety before randomisation began. Then, the first six patients randomised to the ASA404 group were recruited according to early stopping rules to monitor safety before the study progressed further. A detailed pharmacokinetic (PK) evaluation of the ASA404-CP combination was undertaken in these first six patients to assess the potential for drug interaction between ASA404 and paclitaxel and carboplatin in combination. To facilitate this, the ASA404 regimen was modified, with the first cycle of treatment comprising $\mathrm{CP}$, then up to five cycles of ASA404-CP, and finally, for patients still on study, a single cycle of ASA404 alone.

On the basis that no more than one dose-limiting toxicity (DLT), not clearly attributed to paclitaxel or carboplatin, was observed in the first six patients, enrolment continued until approximately 35 eligible patients were recruited in each of the ASA404-CP and CP groups. Treatment was given every 21 days for six cycles or until withdrawal, whichever was earlier. Within-patient dose modification of ASA404 or carboplatin, and crossover between the ASA404$\mathrm{CP}$ and $\mathrm{CP}$ arms were not permitted. The dose of paclitaxel remained unaltered unless dose reduction was required due to toxicity attributed to these agents.

\section{Assessments}

Tumours were measured using computed tomography or magnetic resonance imaging scans. Tumour response was evaluated using RECIST and categorised as complete (CR), partial (PR), stable disease (SD) or progressive disease (PD). Response was confirmed by examination $\geqslant 4$ weeks after first assessment. An independent outcomes committee carried out a blinded radiological review of all tumour assessments.

Safety assessments included a symptom-directed clinical examination before each cycle, 8 and 15 days after drug administration (first six patients only) and at the safety follow-up visit. Laboratory safety assessments of haematology and biochemistry parameters were conducted at these same time points.

Intensive electrocardiographic assessments were conducted throughout the study. Three standard 12-lead ECGs were acquired during the 30 min before paclitaxel administration (at cycles 1, 2 and 6 for the first six patients receiving ASA404; at cycles 1 and 6 for all other patients), and at the end of carboplatin infusion (at cycle 1 for the first six patients receiving ASA404). Single ECGs were collected immediately before administration of ASA404 then at 10,20,60 min and 1,2 and $4 \mathrm{~h}$ from the start of the ASA404 infusion (at cycles 2 and 6 for the first six patients receiving ASA404; at cycles 1 and 6 for all other patients). Electrocardiograms were also collected immediately before paclitaxel infusion and ASA404 infusion, and $1 \mathrm{~h}$ from the start of infusion (at cycles 3, 4 and 5 for the first six patients receiving ASA404; at cycles 2-5 for all other patients).

If a patient developed a QTc interval (Bazett's correction) $>520 \mathrm{~ms}$ (men) or $>540 \mathrm{~ms}$ (women), further ECGs were acquired until the QTc interval returned to within $30 \mathrm{~ms}$ of baseline on two consecutive ECGs.

In patients receiving ASA404, ophthalmic tests were performed before treatment and at follow-up. These included best-corrected visual acuity, ophthalmological examination, contrast sensitivity, colour vision/colour contrast sensitivity and central visual field.

For the first six patients recruited according to early stopping rules, serial PK samples were collected and analysed after carboplatin and paclitaxel dosing at cycle 1, after ASA404, carboplatin and paclitaxel dosing at cycle 2, and after ASA404 monotherapy, 3 weeks after the end of cycle 6 . Total and free concentrations for each drug were determined before infusion, at 
the end of infusion and at various intervals following the end of infusion.

In addition, plasma samples were analysed for 5-HIAA concentration at 2 and $4 \mathrm{~h}$ following the start of ASA404 dosing on day 1 of cycle 2 .

All patients attended a screening visit $\leqslant 28$ days before treatment, a study visit every week and a follow-up visit 4 weeks after study completion/withdrawal. Tumours were measured every 6 weeks until disease progression. Survival was assessed every 3 months.

\section{Statistical methodology and analysis}

Study populations were defined prospectively. Eligible patients met the inclusion criteria and received $\geqslant 1$ dose of study treatment. An intention-to-treat (ITT) population (all patients allocated to treatment) was not prospectively defined.

According to the protocol, efficacy analyses were performed on all eligible patients who received ASA404-CP or CP and safety analyses were performed on all patients who received $\geqslant 1$ dose of study treatment. The single patient who received ASA404 at a dose of $600 \mathrm{mg} \mathrm{m}^{-2}$ was excluded from the analysis of safety and efficacy.

Primary safety outcomes were treatment-emergent adverse events (AEs), laboratory abnormalities, effect on QTc interval and ophthalmic toxicity. A treatment-emergent $\mathrm{AE}$ was defined as any unfavourable and unintended sign, symptom or disease temporally associated with the use of a medicinal product (including abnormal laboratory findings or worsening of preexisting conditions), whether or not considered related to the study drug.

Adverse events were listed using MedDRA coding and graded according to the National Cancer Institute Common Terminology Criteria for Adverse Events (NCI-CTCAE) version 3.0, or as mild, moderate or severe if NCI-CTCAE were not applicable. Relationships of AEs to treatment were assessed as definite, probable, possible or unrelated.

Plasma concentrations of ASA404, carboplatin and paclitaxel were summarised at each time point, for each ASA404 dose and treatment cycle. Mean maximum observed concentration $\left(C_{\max }\right)$ and AUC from time of dosing to time of last observation $\left(\mathrm{AUC}_{(0-\mathrm{t})}\right)$ were calculated and expressed as a ratio (co-administration/alone).

Principal efficacy end points were objective response rates, time to tumour progression (TTP) and survival. According to the protocol, TTP and survival were defined as time from treatment initiation to first objective documentation of progression or death, respectively. In the absence of progression (TTP end point) or death (survival end point), data were 'censored' at the last followup date. Kaplan-Meier curves were fitted for TTP and survival and used to estimate median and 1-year values.

Treatment differences between the ASA404 plus CP and CPalone groups were assessed by calculating the percentage difference (for response rates) and the hazard ratio (for time to event end points) with the corresponding $95 \%$ confidence interval and $P$-value. Statistically significant differences are indicated by $P<0.05$.

A total sample size of 70 patients was fixed. Assuming an overall response rate of $23 \%$ in the ASA404-CP arm, then the lower limit of the $95 \%$ confidence interval would be at least $10 \%$.

\section{RESULTS}

\section{Patient demographics and disposition}

Of the 76 patients allocated to treatment, three were excluded from the safety population as they received no study medication (ASA404-CP, $n=2$; CP, $n=1$ ); the safety population therefore
Table I Baseline characteristics of randomised patients (safety population)

\begin{tabular}{|c|c|c|}
\hline & $\begin{array}{l}\text { ASA404-CP } \\
(n=37)\end{array}$ & $\mathrm{CP}(n=36)$ \\
\hline Men, $n(\%)$ & $23(62.2)$ & $24(66.7)$ \\
\hline Women, $n(\%)$ & $14(37.8)$ & $12(33.3)$ \\
\hline Age (years), mean \pm s.d. & $59.4 \pm 8.91$ & $61.0 \pm 10.76$ \\
\hline \multicolumn{3}{|l|}{ Histological subtype, n (\%) } \\
\hline Squamous cell carcinoma/undifferentiated & || (29.7) & II (30.6) \\
\hline Adenocarcinoma & $25(67.6)$ & $22(61.1)$ \\
\hline Large cell carcinoma & 0 & $2(5.6)$ \\
\hline Other & । (2.7) & I (2.8) \\
\hline \multicolumn{3}{|l|}{ Stage, n (\%) } \\
\hline Illb & II (29.7) & $13(36.1)$ \\
\hline IV & $26(70.3)$ & $23(63.9)$ \\
\hline \multicolumn{3}{|l|}{ Karnofsky performance status, n (\%) } \\
\hline 70 & I (2.7) & $3(8.3)$ \\
\hline 80 & $9(24.3)$ & $9(25.0)$ \\
\hline 90 & $17(45.9)$ & $14(38.9)$ \\
\hline 100 & $10(27.0)$ & $10(27.8)$ \\
\hline
\end{tabular}

ASA404-CP $=$ ASA404 combined with carboplatin and paclitaxel; $C P=$ carboplatin and paclitaxel; s.d. = standard deviation.

comprised 73 patients (ASA404-CP, $n=37$; CP, $n=36$ ). Three treated patients from the ASA404-CP group were excluded from the eligible population because they did not meet inclusion criteria $(n=1)$ or withdrew before receiving ASA404 $(n=2)$; the eligible population therefore comprised 70 patients (ASA404-CP, $n=34$, $\mathrm{CP}, n=36$ ).

The groups were well balanced for pretreatment characteristics (Table 1). Approximately one-third of patients had squamous cell carcinoma.

\section{Treatment}

The average number of chemotherapy cycles was higher in the ASA404-CP group than in the CP group (4.3 and 3.8 cycles per patient, respectively). Eleven patients in the ASA404-CP group and seven in the $\mathrm{CP}$ group required paclitaxel dose reduction. Cycles were delayed more frequently in the ASA404-CP group than in the $\mathrm{CP}$ group (17.6 and $7.4 \%$ of all cycles, respectively).

\section{Pharmacokinetics}

Pharmacokinetic evaluation was performed for the first six patients with the objective of assessing the potential for drug interaction between ASA404 and paclitaxel and carboplatin.

On cycle 1 for these six patients, the $\mathrm{CP}$ combination was given alone and PK parameters were found to be consistent with published values (Patnaik et al, 2006). On cycle 2, CP was coadministered with ASA404 and the PK parameters were compared with CP alone. Mean PK parameters for carboplatin and paclitaxel on cycle 2, expressed as ratio of those on cycle 1, are shown in Table 2. Co-administration of ASA404 did not fundamentally alter the PK parameters of either carboplatin or paclitaxel.

On cycle 7, ASA404 was administered alone and PK parameters were consistent with those reported previously from phase I studies (McKeage et al, 2006) and with those when coadministered with $\mathrm{CP}$ in this study. Mean PK parameters for ASA404 on cycle 2, expressed as a ratio of those on cycle 7, are shown in Table 2. Co-administration did not alter the mean systemic exposure to total ASA404; however, the $C_{\max }$ and AUC 
Table 2 Ratios (co-administration/alone ${ }^{a}$ ) of mean PK parameters for CP cycle 2/cycle I and for ASA404 cycle 2/cycle $7(n=6)$

\begin{tabular}{lcccccc}
\hline & Total carboplatin $^{\mathbf{b}}$ & Free carboplatin $^{\mathbf{b}}$ & Paclitaxel $^{\mathbf{c}}$ & Paclitaxel metabolite $^{\mathbf{c}}$ & Total ASA404 $^{\mathbf{d}}$ & Free ASA404 $^{\mathbf{d}}$ \\
\hline $\mathrm{A} \cup \mathrm{C}_{(0-\mathrm{t})}$ & 1.19 & 1.38 & 1.10 & 0.96 & 1.05 & 7.95 \\
$95 \% \mathrm{Cl}$ & $0.97,1.41$ & $0.98,1.77$ & $0.93,1.27$ & $0.62,1.29$ & $0.46,1.64$ \\
$\mathrm{C}_{\max }$ & 1.26 & 1.36 & 0.88 & 1.04 & $2.05,13.84$ \\
$95 \% \mathrm{Cl}$ & $0.76,1.76$ & $0.37,2.35$ & $0.69,1.07$ & $0.69,1.40$ & 5.72 & 1.01 \\
\hline
\end{tabular}

${ }^{a}$ In cycle I CP was given alone, in cycle 2 CP was co-administered with ASA404 and in cycle 7 ASA404 was given alone. ${ }^{b} t=20.25 \mathrm{~h}$ for carboplatin. ${ }^{c} t=45 \mathrm{~h}$ for paclitaxel. ${ }_{t}=43.75 \mathrm{~h}$ for ASA404.

values for free ASA404 were increased approximately six- and eight-fold, respectively. Systemic exposure was markedly higher for total ASA404 compared with free ASA404, as expected for an agent that is extensively protein bound (Jameson et al, 2003).

\section{Pharmacodynamics}

Peak levels of 5-HIAA occurred $2 \mathrm{~h}$ after ASA404 dosing. Mean concentrations $(n=5)$ at this time point were $137.2 \pm 46.6 \mathrm{nM}$, representing an increase of $80.6 \pm 26.0 \mathrm{~nm}$ from baseline. This relative increase is similar to that seen with ASA404 $1200 \mathrm{mg} \mathrm{m}^{-2}$ in phase I studies (Rustin et al, 2003a; McKeage et al, 2006).

\section{Safety}

Overall safety profiles were generally similar in the ASA404-CP and CP groups (Table 3), and for squamous and non-squamous patients. Most AEs and serious AEs (SAEs) were attributed to standard therapy components. The proportions of patients with AEs, ASA404- or CP-related AEs, SAEs and deaths, or study discontinuations due to AEs, were similar in the two groups.

The most frequently occurring AEs attributed to ASA404 were infusion site pain, nausea, vomiting and anaemia. The only SAE directly attributed to ASA404 was asthenia in one patient.

The most common grade $3 / 4$ toxicities are shown in Table 4 . Grade 3/4 neutropenia, thrombocytopenia, infection, hypokalemia and infusion site burning or pain occurred more frequently in the ASA404-CP group, whereas grade 3/4 hyperglycaemia, neuropathy and anaemia occurred more frequently in the $\mathrm{CP}$ group.

Other differences noted between the two groups were four grade 3 respiratory AEs (dyspnea $(n=2)$, pneumothorax and productive cough) occurring only in the ASA404-CP group and four grade 3 infections (chronic bronchitis, lung infection, urinary tract infection and viral diarrhoea) occurring in the ASA404-CP group $v s$ one grade 3 infection (lower respiratory tract) occurring in the CP group.

Grade 3/4 haematological abnormalities occurred in 78.4 and $63.9 \%$ patients in the ASA404-CP and CP groups, respectively. The incidence of neutropenia at grade 3/4 was higher in the ASA404-CP group $(62.2 \%)$ than in the CP group $(38.9 \%)$ (difference of $23.3 \%$, $95 \%$ CI 1.0, 45.6). Maximal decreases in neutrophil counts occurred at day 15 after cycle 6 in both groups. Mean absolute neutrophil count fell from $7.54 \pm 3.31 \times 10^{9} 1^{-1}$ at baseline to $1.14 \pm 1.0 \times 10^{9} 1^{-1}$ in the ASA404-CP group, and from $8.23 \pm$ $4.76 \times 10^{9} \mathrm{l}^{-1}$ to $1.54 \pm 0.75 \times 10^{9} \mathrm{l}^{-1}$ in the CP group. Laboratory data also showed that there was a higher overall incidence of thrombocytopenia (all grades) in the ASA404-CP group (62.2 vs $44.4 \%$ ). Other haematological toxicities were similar in the two treatment arms.

The incidences of cardiac AEs and SAEs were higher in the ASA404-CP group than in the CP group (18.9 and $10.8 \%$ vs 8.3 and $2.8 \%$, respectively). Four patients in the ASA404-CP group had cardiac SAEs. These were transient/reversible and included one instance each of tachyarrhythmia (cycle 1, grade 4), cardiomyopathy (cycle 3, patient withdrawn), myocardial ischaemia (cycles 3 and 5) and angina pectoris (cycle 3 , grade 3 ). Three of these patients had a history of cardiovascular disease. Electrocardiogram
Table 3 Summary of treatment-emergent adverse events (safety population)

\begin{tabular}{|c|c|c|}
\hline & \multicolumn{2}{|c|}{ No. of patients (\%) } \\
\hline & ASA404-CP $(n=37)$ & $C P(n=36)$ \\
\hline$\geqslant 1$ adverse event & $34(91.9)$ & $36(100.0)$ \\
\hline Related to ASA404 & $27(73.0)$ & - \\
\hline Related to standard therapy & $28(75.7)$ & $31(86.1)$ \\
\hline Grade $1^{a} /$ mild $^{b}$ & $3(8.1)$ & $4(11.1)$ \\
\hline Grade $2^{\mathrm{a}} /$ moderate $\mathrm{b}$ & $6(16.2)$ & $8(22.2)$ \\
\hline Grade $3^{\mathrm{a}} /$ severe $^{\mathrm{b}}$ & $17(45.9)$ & $22(61.1)$ \\
\hline Grade $4^{\mathrm{a}, \mathrm{b}}$ & $5(13.5)$ & 0 \\
\hline Grade $5^{\mathrm{a}, \mathrm{b}}$ & $3(8.1)$ & $2(5.6)$ \\
\hline$\geqslant 1$ serious adverse event & $16(43.2)$ & $17(47.2)$ \\
\hline Related to ASA404 & | (2.7) & 0 \\
\hline Related to standard therapy & $5(13.5)$ & $6(16.7)$ \\
\hline Adverse event leading to death & $2(5.4)$ & $2(5.6)$ \\
\hline Adverse event leading to withdrawal & $5(13.5)$ & $9(25.0)$ \\
\hline
\end{tabular}

ASA404-CP $=$ ASA404 combined with carboplatin and paclitaxel; $C P=$ carboplatin and paclitaxel. ${ }^{a}$ National Cancer Institute Common Terminology Criteria for Adverse Events grading. 'Worst severity grade.

analyses showed only one patient in the ASA404-CP group with a prolonged QTc interval.

No patient showed significant deterioration in ophthalmic variables after ASA404 treatment. Five AEs associated with visual function (irritation, blurred vision or visual disturbance) were seen in the ASA404-CP group and four were seen in the standard therapy group (blurred vision or visual disturbance). All visual function AEs were of < grade 3 severity.

Adverse events leading to withdrawal included disease progression (ASA404-CP, $n=1 ; \mathrm{CP}, n=3$ ); anaphylactic reaction, paclitaxel reaction, hypersensitivity or premedication reaction (ASA404-CP, $n=1$; CP, $n=3$ ); leucopenia, neutropenia or thrombocytopenia (ASA404-CP, $n=2 ; \mathrm{CP}, n=1$ ); peripheral neuropathy (CP, $n=1)$; cardiomyopathy (ASA404-CP, $n=1$ ); and multiple chemotherapy toxicities ( $\mathrm{CP}, n=1)$.

Seven deaths occurred on-study in the safety population (ASA404-CP, $n=4$; CP, $n=3$ ). These were attributed to disease progression (ASA404-CP, $n=2 ; \mathrm{CP}, n=1$ ), pulmonary oedema (CP, $n=1)$, pulmonary haemorrhage (CP, $n=1)$, sepsis (ASA404$\mathrm{CP}, n=1$ ) and non-obvious reasons (ASA404-CP, $n=1$ ).

\section{Efficacy}

Table 5 shows RECIST response outcomes. Investigator assessment gave a best overall response of PR, with $34.4 \%$ (95\% CI 17.9, 50.8) and $29.0 \%(95 \%$ CI $13.1,45.0)$ responses confirmed in the ASA404$\mathrm{CP}$ group and $\mathrm{CP}$ group, respectively.

Independent assessment showed that a greater proportion of patients receiving ASA404 had a best overall response of PR with $31.3 \%(95 \%$ CI $15.2,47.3)$ vs $22.2 \%$ (95\% CI 6.5, 37.9) with CP, 
Table 4 Most common grade 3 and 4 toxicities (safety population)

\begin{tabular}{|c|c|c|c|c|}
\hline Toxicity & \multicolumn{4}{|c|}{ No. of patients (\%) } \\
\hline Neutropenia & $8(21.6)$ & $15(40.5)$ & $10(27.8)$ & $4(11.1)$ \\
\hline Leukopenia & $5(13.5)$ & $5(13.5)$ & $9(25.0)$ & I (2.8) \\
\hline Alopecia & $7(18.9)$ & I (2.7) & $10(27.8)$ & 0 \\
\hline Anaemia & $3(8.1)$ & 0 & $5(13.9)$ & 0 \\
\hline Thrombocytopenia & $2(5.4)$ & $2(5.4)$ & $2(5.6)$ & 0 \\
\hline Gastrointestinal disorders & $3(8.1)$ & 0 & $2(5.6)$ & | (2.8) \\
\hline Infection & $4(10.8)$ & 0 & I (2.8) & 0 \\
\hline Arthralgia, back or extremity pain & $2(5.4)$ & 0 & $3(8.3)$ & 0 \\
\hline Cardiac disorders & $3(8.1)$ & I (2.7) & I (2.8) & 0 \\
\hline Hypokalaemia & $3(8.1)$ & 0 & 0 & 0 \\
\hline Neoplasms benign, malignant and unspecified & 0 & 0 & $2(5.6)$ & 0 \\
\hline Flushing or hypotension & 0 & 0 & $2(5.6)$ & 0 \\
\hline Febrile neutropenia & 0 & I (2.7) & I (2.8) & 0 \\
\hline
\end{tabular}

$\mathrm{ASA} 404-\mathrm{CP}=\mathrm{ASA} 404$ combined with carboplatin and paclitaxel; $\mathrm{CP}=$ carboplatin and paclitaxel.

Table 5 Tumour response rate (eligible population)

\begin{tabular}{|c|c|c|}
\hline & \multicolumn{2}{|c|}{ No. of patients (\%) } \\
\hline & $\begin{array}{l}\text { ASA404-CP } \\
\quad(n=34)\end{array}$ & $\begin{array}{c}C P \\
(n=36)\end{array}$ \\
\hline \multicolumn{3}{|l|}{ Investigator assessment } \\
\hline $\begin{array}{l}\text { Number of patients available for } \\
\text { assessment }\end{array}$ & $32(100.0)$ & $31(100.0)$ \\
\hline Partial response (confirmed) & II (34.4) & $9(29.0)$ \\
\hline Partial response (unconfirmed) & $2(6.3)$ & $3(9.7)$ \\
\hline Stable disease & $14(43.8)$ & $10(32.3)$ \\
\hline Progressive disease & $5(15.6)$ & $9(29.0)$ \\
\hline \multicolumn{3}{|l|}{ Independent assessment } \\
\hline $\begin{array}{l}\text { Number of patients available for } \\
\text { assessment } \mathrm{t}^{\mathrm{a}}\end{array}$ & $32(100.0)$ & $27(100.0)$ \\
\hline Partial response & $10(31.3)$ & $6(22.2)$ \\
\hline Stable disease & $21(65.6)$ & $19(70.4)$ \\
\hline Progressive disease & I (3.1) & $2(7.4)$ \\
\hline
\end{tabular}

ASA404-CP $=$ ASA404 combined with carboplatin and paclitaxel; $C P=$ carboplatin and paclitaxel. ${ }^{a}$ Tumour response could not be evaluated in II eligible patients by independent assessment due to: patient death before second tumour assessment $(n=3)$; patient withdrawal before second tumour assessment $(n=3)$; disease progression after cycle I and no subsequent scans available $(n=2)$; no target lesion present $(n=2)$; or no baseline scan available $(n=1)$.

although it should be noted that 11 patients could not be evaluated for response.

Median TTP by investigator assessment was 5.4 month in the ASA404-CP group and 4.4 months in the CP group (Figure 1). The risk of progression was reduced by $14 \%$ in the ASA404-CP group, with a hazard ratio of $0.86,95 \%$ CI $0.51,1.45$, and $P=0.56$ (for the ITT population: hazard ratio $0.94,95 \% \mathrm{CI} 0.56,1.57, P=0.82$ ).

Median survival was 14.0 months in the ASA404-CP group and 8.8 months in the CP group (Figure 2). The risk of death was reduced by $27 \%$ in the ASA404-CP group, with a hazard ratio of $0.73,95 \%$ CI $0.39,1.38$, and $P=0.33$ (for the ITT population:

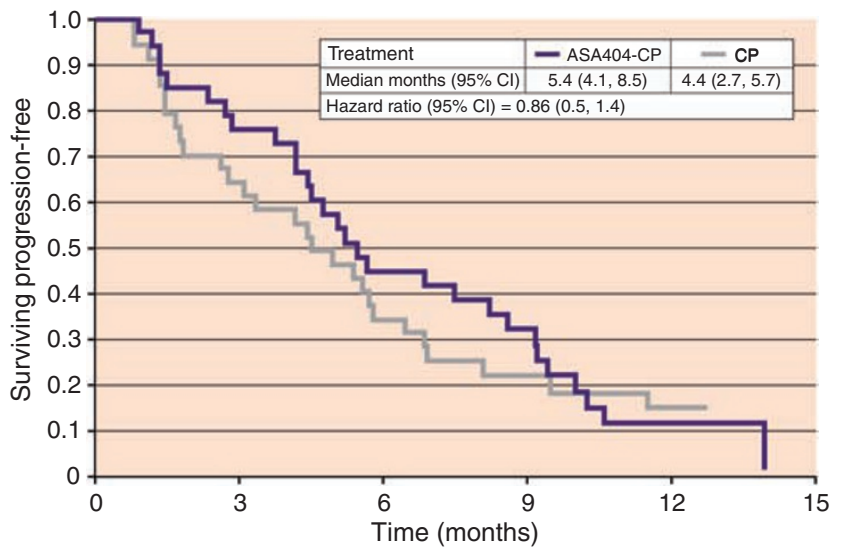

Figure I Kaplan-Meier estimate of the time to tumour progression; eligible population (ASA404-CP $n=34, C P n=36$ ).

hazard ratio $0.86,95 \%$ CI $0.47,1.57, P=0.63)$. One-year survival was $50.0 \%$ in the ASA404-CP group and $42.1 \%$ in the CP group.

\section{DISCUSSION}

This randomised phase II study evaluated the feasibility of adding the Tumour-VDA ASA404 to a standard regimen of carboplatin and paclitaxel in patients with previously untreated, advanced NSCLC.

The study showed that when ASA404 was co-administered with carboplatin and paclitaxel, there was little change in the systemic exposure or disposition of either total or free carboplatin or paclitaxel/6-alpha-hydroxy paclitaxel. Similarly, co-administration with this standard therapy did not markedly alter the systemic exposure of total ASA404. However, the concentration of free ASA404 was increased, suggesting that the chemotherapy drugs or excipients altered the partitioning of ASA404 within plasma. 


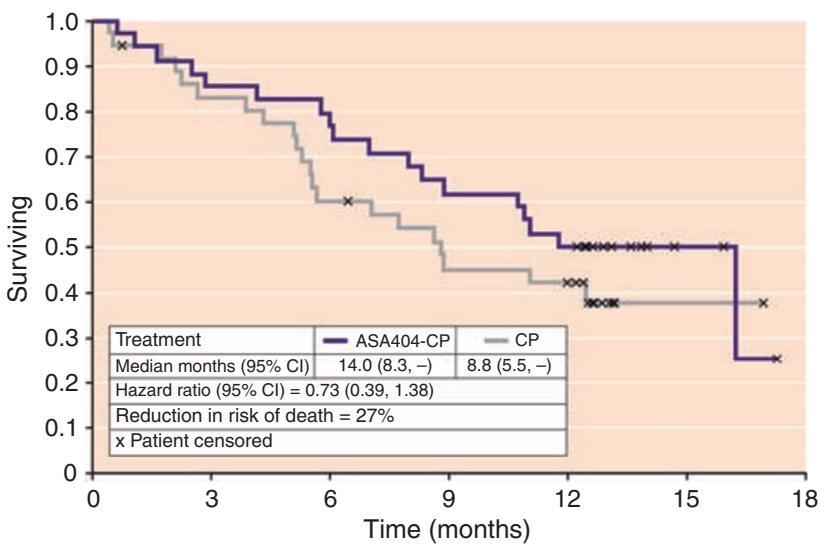

Figure 2 Kaplan-Meier estimate of the probability of survival; eligible population (ASA404-CP $n=34$, CP $n=36$ ).

The addition of ASA404 to carboplatin and paclitaxel was generally well tolerated and did not produce prohibitive additional toxicity. The ASA404-CP group had a similar overall safety profile to the CP group in that the incidences of AEs, SAEs and deaths or study discontinuations due to AEs were similar. The higher incidences of neutropenia, thrombocytopenia and infection in the ASA404-CP group compared with the CP group were not expected on the basis of the safety profile for ASA404 monotherapy (Jameson et al, 2003; Rustin et al, 2003a; McKeage et al, 2006). However, these were generally manageable and acceptable.

Intensive assessments showed that ophthalmic AEs occurred with similar incidences in the ASA404-CP and CP groups. No patient showed clinically relevant deterioration in ophthalmological parameters after ASA404 treatment. This suggests that ASA404 $1200 \mathrm{mg} \mathrm{m}^{-2}$ can be combined with carboplatin and paclitaxel without the potential for the ophthalmic AEs seen at higher monotherapy doses (Galbraith et al, 2002; McKeage et al, 2006).

The incidence of cardiac AEs and SAEs was higher in the ASA404-CP group than in the CP group, although a causal relationship to ASA404 was not established. It can be noted that most of the cardiac SAEs in the ASA404-CP group occurred in patients with known cardiovascular disease. Furthermore, in phase I studies of ASA404, the predominant cardiac AE was QTc interval prolongation (Jameson et al, 2003; McKeage et al, 2006), of which there was a low incidence in this study. Nonetheless, as cardiac toxicity could result from the mechanism of action of VDAs
(Cooney et al, 2004), the cardiac safety profile of ASA404 should continue to be monitored in future studies.

Although the study was not powered to compare efficacy outcomes statistically, the ASA404 combination appeared to improve a range of efficacy end points compared with carboplatin and paclitaxel alone - most notably overall survival. Response rates and survival in the $\mathrm{CP}$ group were similar to those reported previously for a carboplatin and paclitaxel regimen in patients with advanced NSCLC (Schiller et al, 2002).

The magnitude of improvement in TTP was more modest than that seen for overall survival. One possible explanation is that radiological measurements and RECIST may not detect the antitumour effects exerted by ASA404 because these are predominantly at the tumour core.

In a phase II study, addition of bevacizumab to a carboplatin and paclitaxel regimen in the same setting as in our study was associated with fatal pulmonary haemorrhage in patients with squamous histology (Johnson et al, 2004). A more recent study of the addition of the anti-angiogenic multiple kinase inhibitor sorafenib to carboplatin and paclitaxel also indicated a higher mortality rate in sorafenib-treated patients with squamous NSCLC (Scagliotti et al, 2008). Despite approximately one-third of patients in our study having squamous histology, only one episode of major pulmonary haemorrhage was documented and this occurred in the CP group. Other vascular-related side effects associated with bevacizumab (hypertension, proteinuria and epistaxis) (Johnson et al, 2004) were not prominent in the ASA404-CP group.

In conclusion, this study establishes the feasibility of combining ASA404 with a standard chemotherapy regimen of carboplatin and paclitaxel in patients with previously untreated, advanced NSCLC. The manageable safety profile, lack of adverse pharmacokinetic interactions and apparent improvements in various efficacy parameters associated with the addition of ASA404 to carboplatin and paclitaxel support the initiation of a phase III trial of sufficient size to test this novel combination regimen with statistical power.

\section{ACKNOWLEDGEMENTS}

This study was supported by Antisoma Research Limited, London, UK. We thank the patients, families, study staff and the Antisoma clinical development team. The following investigators contributed patients to the study in addition to the authors: Michael Boyer, Royal Prince Alfred Hospital, Sydney, Australia; Michael J Byrne, Sir Charles Gairdner Hospital, Perth, Australia; Vinod Gandju, Frankston Hospital, Frankston, Australia.

\section{REFERENCES}

Baguley BC (2003) Antivascular therapy of cancer: DMXAA. Lancet Oncol 4: 141 - 148, doi:10.1016/S1470-2045(03)01018-0

Baguley BC, Zhuang L, Kestell P (1997) Increased plasma serotonin following treatment with flavone-8-acetic acid, 5,6-dimethylxanthenone4 -acetic acid, vinblastine, and colchicine: relation to vascular effects. Oncol Res 9: 55-60

Ching LM, Cao Z, Kieda C, Zwain S, Jameson MB, Baguley BC (2002) Induction of endothelial cell apoptosis by the antivascular agent 5 , 6-Dimethylxanthenone-4-acetic acid. Br J Cancer 86: 1937-1942, doi:10.1038/sj.bjc.6600368

Ching LM, Goldsmith D, Joseph WR, Korner H, Sedgwick JD, Baguley BC (1999) Induction of intratumoral tumor necrosis factor (TNF) synthesis and hemorrhagic necrosis by 5,6-dimethylxanthenone-4-acetic acid (DMXAA) in TNF knockout mice. Cancer Res 59: 3304-3307

Ching LM, Zwain S, Baguley BC (2004) Relationship between tumour endothelial cell apoptosis and tumour blood flow shutdown following treatment with the antivascular agent DMXAA in mice. Br J Cancer 90: 906-910, doi:10.1038/sj.bjc.6601606
Cooney MM, Radivoyevitch T, Dowlati A, Overmoyer B, Levitan N, Robertson K, Levine SL, DeCaro K, Buchter C, Taylor A, Stambler BS, Remick SC (2004) Cardiovascular safety profile of combretastatin A4 phosphate in a single-dose phase I study in patients with advanced cancer. Clin Cancer Res 10: $96-100$

Dowlati A, Robertson K, Cooney M, Petros WP, Stratford M, Jesberger J, Rafie N, Overmoyer B, Makkar V, Stambler B, Taylor A, Waas J, Lewin JS, McCrae KR, Remick SC (2002) A phase I pharmacokinetic and translational study of the novel vascular targeting agent combretastatin a-4 phosphate on a single-dose intravenous schedule in patients with advanced cancer. Cancer Res 62: 3408-3416

Galbraith SM, Rustin GJ, Lodge MA, Taylor NJ, Stirling JJ, Jameson M, Thompson P, Hough D, Gumbrell L, Padhani AR (2002) Effects of 5,6dimethylxanthenone-4-acetic acid on human tumor microcirculation assessed by dynamic contrast-enhanced magnetic resonance imaging. $J$ Clin Oncol 20: $3826-3840$

Jameson MB, Thompson PI, Baguley BC, Evans BD, Harvey VJ, Porter DJ, McCrystal MR, Small M, Bellenger K, Gumbrell L, Halbert GW, Kestell P 
(2003) Clinical aspects of a phase I trial of 5,6-dimethylxanthenone4-acetic acid (DMXAA), a novel antivascular agent. Br J Cancer 88: 1844 - 1850, doi:10.1038/sj.bjc.6600992

Johnson DH, Fehrenbacher L, Novotny WF, Herbst RS, Nemunaitis JJ, Jablons DM, Langer CJ, DeVore III RF, Gaudreault J, Damico LA, Holmgren E, Kabbinavar F (2004) Randomized phase II trial comparing bevacizumab plus carboplatin and paclitaxel with carboplatin and paclitaxel alone in previously untreated locally advanced or metastatic non-small-cell lung cancer. J Clin Oncol 22: 2184-2191, doi:10.1200/ JCO.2004.11.022

Joseph WR, Cao Z, Mountjoy KG, Marshall ES, Baguley BC, Ching LM (1999) Stimulation of tumors to synthesize tumor necrosis factor-alpha in situ using 5,6-dimethylxanthenone-4-acetic acid: a novel approach to cancer therapy. Cancer Res 59: 633-638

Langer CJ, Leighton JC, Comis RL, O'Dwyer PJ, McAleer CA, Bonjo CA, Engstrom PF, Litwin S, Ozols RF (1995) Paclitaxel and carboplatin in combination in the treatment of advanced non-small-cell lung cancer: a phase II toxicity, response, and survival analysis. J Clin Oncol 13: $1860-1870$

Laws AL, Matthew AM, Double JA, Bibby MC (1995) Preclinical in vitro and in vivo activity of 5,6-dimethylxanthenone-4-acetic acid. Br J Cancer 71: $1204-1209$

McKeage MJ, Fong P, Jeffery M, Baguley BC, Kestell P, Ravic M, Jameson MB (2006) 5,6-dimethylxanthenone-4-acetic Acid in the treatment of refractory tumors: a phase I safety study of a vascular disrupting agent. Clin Cancer Res 12: $1776-1784$

McKeage MJ, Kelland LR (2006) 5,6-Dimethylxanthenone-4-acetic acid (DMXAA); clinical potential in combination with taxane-based chemotherapy. Am J Cancer 5: 155-162

McKeage MJ, Kestell P, Denny WA, Baguley BC (1991) Plasma pharmacokinetics of the antitumour agents 5,6-dimethylxanthenone-4acetic acid, xanthenone-4-acetic acid and flavone-8-acetic acid in mice. Cancer Chemother Pharmacol 28: 409-413, doi:10.1007/BF00685815

Murata R, Siemann DW, Overgaard J, Horsman MR (2001) Improved tumor response by combining radiation and the vascular-damaging drug 5,6-dimethylxanthenone-4-acetic acid. Radiat Res 156: 503-509, 10.1667/ 0033-7587(2001)156[0503:ITRBCR]2.0.CO;2

Non-small Cell Lung Cancer Collaborative Group (1995) Chemotherapy in non-small cell lung cancer: a meta-analysis using updated data on individual patients from 52 randomised clinical trials. $\mathrm{Br}$ Med J 311: 899-909

Patnaik A, Wood D, Tolcher AW, Hamilton M, Kreisberg JI, Hammond LA, Schwartz G, Beeram M, Hidalgo M, Mita MM, Wolf J, Nadler P, Rowinsky EK (2006) Phase I, pharmacokinetic, and biological study of erlotinib in combination with paclitaxel and carboplatin in patients with advanced solid tumors. Clin Cancer Res 12: $7406-7413$

Pruijn FB, van Daalen M, Holford NH, Wilson WR (1997) Mechanisms of enhancement of the antitumour activity of melphalan by the tumourblood-flow inhibitor 5,6-dimethylxanthenone-4-acetic acid. Cancer Chemother Pharmacol 39: 541 -546, doi:10.1007/s002800050611
Rustin GJ, Bradley C, Galbraith S, Stratford M, Loadman P, Waller S, Bellenger K, Gumbrell L, Folkes L, Halbert G (2003a) 5,6-dimethylxanthenone-4-acetic acid (DMXAA), a novel antivascular agent: phase I clinical and pharmacokinetic study. Br J Cancer 88: 1160-1167, doi:10.1038/sj.bjc.6600885

Rustin GJ, Galbraith SM, Anderson H, Stratford M, Folkes LK, Sena L, Gumbrell L, Price PM (2003b) Phase I clinical trial of weekly combretastatin A4 phosphate: clinical and pharmacokinetic results. J Clin Oncol 21: 2815-2822, doi:10.1200/JCO.2003.05.185

Sandler A, Gray R, Perry MC, Brahmer J, Schiller JH, Dowlati A, Lilenbaum R, Johnson DH (2006) Paclitaxel - carboplatin alone or with bevacizumab for non-small-cell lung cancer. N Engl J Med 355: 2542-2550

Scagliotti G, von Pawel J, Reck M, Cupit L, Cihon F, Dimatteo S, O’Leary J, Hanna N (2008) Sorafenib plus carboplatin/paclitaxel in chemonaive patients with stage IIIb-IV nonsmall cell lung cancer (NSCLC): interim analysis (IA) results from the phase III, randomized, doubleblind, placebo-controlled, ESCAPE (evaluation of sorafenib, carboplatin, and paclitaxel efficacy in NSCLC) trial. Late breaking abstract presented at 1st European Lung Cancer Conference

Schiller JH, Harrington D, Belani CP, Langer C, Sandler A, Krook J, Zhu J, Johnson DH (2002) Comparison of four chemotherapy regimens for advanced non-small-cell lung cancer. $N$ Engl J Med 346: $92-98$

Siim BG, Lee AE, Shalal-Zwain S, Pruijn FB, McKeage MJ, Wilson WR (2003) Marked potentiation of the antitumour activity of chemotherapeutic drugs by the antivascular agent 5,6-dimethylxanthenone-4-acetic acid (DMXAA). Cancer Chemother Pharmacol 51: 43-52, doi:10.1007/s00280-002-0529-0

Stevenson JP, Rosen M, Sun W, Gallagher M, Haller DG, Vaughn D, Giantonio B, Zimmer R, Petros WP, Stratford M, Chaplin D, Young SL, Schnall M, O'Dwyer PJ (2003) Phase I trial of the antivascular agent combretastatin A4 phosphate on a 5-day schedule to patients with cancer: magnetic resonance imaging evidence for altered tumor blood flow. J Clin Oncol 21: $4428-4438$

Therasse P, Arbuck SG, Eisenhauer EA, Wanders J, Kaplan RS, Rubinstein L, Verweij J, Van Glabbeke M, van Oosterom AT, Christian MC, Gwyther SG (2000) New guidelines to evaluate the response to treatment in solid tumors. European Organization for Research and Treatment of Cancer, National Cancer Institute of the United States, National Cancer Institute of Canada. J Natl Cancer Inst 92: 205-216

Tozer GM, Kanthou C, Baguley BC (2005) Disrupting tumour blood vessels. Nat Rev Cancer 5: 423-435, doi:10.1038/nrc1628

Wakelee H, Belani CP (2005) Optimizing first-line treatment options for patients with advanced NSCLC. Oncologist 10(Suppl 3): 1-10, doi:10.1634/theoncologist.10-90003-1

Wilson WR, Li AE, Cowan DS, Siim BG (1998) Enhancement of tumor radiation response by the antivascular agent 5,6-dimethylxanthenone-4acetic acid. Int J Radiat Oncol Biol Phys 42: 905-908, doi:10.1016/S03603016(98)00358-7

Zwi LJ, Baguley BC, Gavin JB, Wilson WR (1994) Correlation between immune and vascular activities of xanthenone acetic acid antitumor agents. Oncol Res 6: 79-85 